\title{
Study of fetomaternal outcome of teenage pregnancy in a tertiary care hospital-MGMGH
}

\section{Gayathrie Devi, Kayalvizhi, Poovathi M.*}

Department of Obstetrics and Gynecology, Mahatma Gandhi Memorial Government Hospital attached to K. A. P. V. Medical College, Trichy, Tamil Nadu, India

Received: 03 November 2018

Accepted: 06 December 2018

\author{
*Correspondence: \\ Dr. Poovathi M., \\ E-mail: drmpoovathi@gmail.com
}

Copyright: (c) the author(s), publisher and licensee Medip Academy. This is an open-access article distributed under the terms of the Creative Commons Attribution Non-Commercial License, which permits unrestricted non-commercial use, distribution, and reproduction in any medium, provided the original work is properly cited.

\begin{abstract}
Background: The objective is to study the fetomaternal outcome in teenage pregnancy at MGMGH for the study period of 6 months from April 2018 to September 2018. Teenage pregnancy is a worldwide health problem. WHO defined adolescence as the period from 10-19 years. It is a serious health problem in a developing country like India. Teenage pregnancy is associated with high risk of prematurity, low birthweight, preeclampsia and anaemia. The NHFS IV 2015 -2016 estimates that overall teenage pregnancy in India 7.9\%.

Methods: It is a retrospective study conducted in a tertiary care hospital at MGMGH, Trichy over a period of 6 months.251 teenage pregnant women delivered at our institution were selected for the study out of 4508 total deliveries during the study period. Parameters including incidence, age, parity, booking status, educational and socioeconomic status, medical disorders, antepartum, intrapartum, postpartum complications, mode of delivery and neonatal outcome were studied.

Results: Study showed the incidence of teenage pregnancy at our MGMGH is $5.56 \%$. Among these teenage pregnant women $47.1 \%$ had anaemia, $23.1 \%$ had gestational hypertension, $4.8 \%$ of women had eclampsia, $22.3 \% \%$ had preterm delivery. Lscs rate was $27.1 \%, 70.29 \%$ had Normal vaginal delivery, $1.6 \%$ had instrumental deliveries, $31.5 \%$ had low birth weight babies, $28.2 \%$ NICU admissions, $2.9 \%$ perinatal deaths.

Conclusions: Teenage pregnancy is associated with increased incidence of anaemia, pre-eclampsia, eclampsia, preterm delivery, instrumental delivery, low birth weight and perinatal death. By improving socio economic status, education, nutrition, good antenatal care, public awareness, institutional delivery and postnatal care help in reducing maternal and perinatal morbidity and mortality in adolescent pregnancy.
\end{abstract}

Keywords: Adolescent, Anaemia, Eclampsia, Pre-eclampsia, Teenage pregnancy

\section{INTRODUCTION}

Teenage pregnancy is a worldwide health problem. WHO defined teenage pregnancy as any pregnancy from a girl who is 10 to 19 years of age, age being defined as her age at the time of delivery. ${ }^{1}$ According to National family health survey-4 2015-2016 revealed that incidence of teenage pregnancy in India were $7.9 \% .^{2}$ India has successfully reduced the proportion of teenage pregnancy which was $16 \%$ during the NFHS-3 in 2005-2006 and it was $7.9 \%$ during NFHS-4 2015-2016. Highest prevalence seen in Bihar, West Bengal, Jharkhand, Rajasthan, Assam, Maharashtra, Madhya Pradesh, Gujarat, Tripura Andhra Pradesh, Uttar Pradesh, Telangana, Karnataka, Odisha.

Incidence to teenage pregnancy in India is 2 women out of 1000 pregnancies. If pregnancy occurs during teenage 
period nutrition must suffice the growth of the mother in addition to the baby. The outcomes were influenced by this biological immaturity, unintended pregnancy, inadequate perinatal care, poor maternal nutrition and stress. The outcomes are more adverse in the lower teenage group of 13-15 years than in the higher teenage group of 16 to 19 years. ${ }^{3}$ The combination of poor nutrition and early child bearing expose young women to serious health problems during pregnancy and child birth, including damage to the reproductive tract, pregnancy related complications like anaemia, preeclampsia, eclampsia, preterm labour, cephalon pelvic disproportion, low birth weight. ${ }^{4,5}$ Adolescents face barriers to access contraceptive devices because of inadequate sexual health.

WHO guidelines in 2011 on preventing adolescent pregnancies, 6 main objectives: ${ }^{6}$

1. Decreasing marriage before the age of 18 years.

2. Creating understanding and support to reduce pregnancy before the age of 20 years.

3. Increasing the use of contraception.

4. Reducing coerced sex among adolescents.

5. Reducing unsafe abortion among adolescents.

6. Increasing use of skilled antenatal, child birth and postnatal care among adolescents.

\section{METHODS}

It is a retrospective study conducted at Government $\mathrm{K}$. A. P. V. medical college, MGMGH Trichy during April 2018 to September 2018 among teenage pregnant women. Fetomaternal outcome were studied in all teenage girls (completed age less than or equal to 19) who were admitted in our hospital. Data's are a like Name, age, address, duration of pregnancy, date of last menstrual period, expected date of delivery, booking status, number of antenatal visits were taken. General physical and obstetrical examination was done. Investigations like Hemoglobin, Blood grouping typing, Blood random blood sugar, urine routine was taken. Data like obstetric code, educational status, antepartum, intrapartum, postpartum complications, mode of delivery, whether normal vaginal delivery or lower segment caesarean section were collected. Neonatal outcome in terms of preterm, low birthweight, still birth, NICU admission were collected.

\section{Inclusion criteria}

- All teenage pregnant women visiting Govt K. A. P. V. Medical College, MGMGH.

- Age 15-19 years.

- $\quad$ Primi/multi gravida.

\section{Exclusion criteria}

- $\quad$ Age $>20$ years.

\section{RESULTS}

During the study period from April 2018-September 2018, 4508 pregnant women were admitted in our hospital for delivery and abortion. Out of this teenage pregnant woman were 251 . Hence proportion of teenage pregnancies were $5.56 \%$. Out of 251 teenage pregnant women, $210(83.3 \%)$ were of 19 years of age and 41 $(16.7 \%)$ were of 18 years of age.

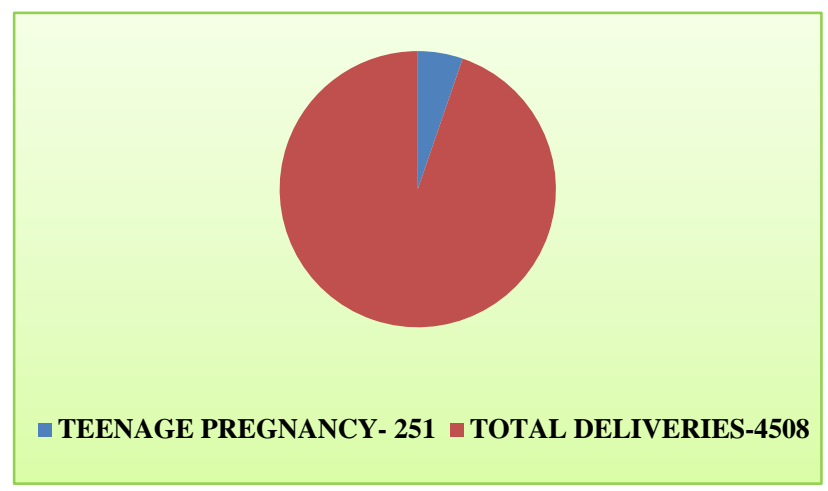

Figure 1: Incidence of teenage pregnancy at MGMGH.

As per Figure 1, 251 teenage pregnant women delivered at our institution were selected for the study out of 4508 total deliveries during the study period and the incidence at MGMGH is $5.56 \%$.

Table 1: Incidence of teenage pregnancy among primi and multigravida at MGMGH.

\begin{tabular}{|l|l|l|}
\hline Gravida & No & Percentage \\
\hline Primi & 211 & 84 \\
\hline Second gravida & 34 & 13.54 \\
\hline Third gravida & 6 & 2.3 \\
\hline
\end{tabular}

Table1 shows the incidence at MGMGH 211 (84\%) of pregnant adolescents were primigravida, 34(13.54\%) $34(13.5 \%)$ were second gravid, $6(2.3 \%)$ were third gravida.

Table 2: Educational status of teenage pregnancy at MGMGH.

\begin{tabular}{|l|l|l|}
\hline Educational Status & No & Percentage \\
\hline Primary education & 165 & 65.8 \\
\hline Secondary education & 86 & 34.2 \\
\hline
\end{tabular}

Table 2 describes the educational status of present study and it revealed that $165(65.8 \%)$ had primary education and $86(34.2 \%)$ had secondary education. None were studying at a college.

Table 3 describes the antepartum complications among teenage pregnancy-119(47.1\%) of pregnant adolescents had anaemia, gestational hypertension 57(23.1\%) and 
eclampsia occurred in12(4.8\%), abruption placenta $3(1.1 \%)$, malpresentation $11(4.38 \%)$.

Table 3: Antepartum complications in teenage pregnancy.

\begin{tabular}{|l|l|l|}
\hline Type of complications & $\begin{array}{l}\text { Number } \\
\text { of cases }\end{array}$ & Percentage \\
\hline Anaemia & 119 & 47.1 \\
\hline Gestational hypertension & 57 & 23.1 \\
\hline Eclampsia & 12 & 4.8 \\
\hline Abruptio placenta & 3 & 1.1 \\
\hline Still birth & 22 & 9.1 \\
\hline Malpresentation & 11 & 4.38 \\
\hline
\end{tabular}

First trimester abortion occurred in $7(2.78 \%)$ and second trimester abortion in $3(1.19 \%)$, Ectopic pregnancy in $2(0.79 \%)$.

Table 4: Intrapartum complications in teenage pregnancy.

\begin{tabular}{|l|l|l|}
\hline Type of complications & Number & Percentage \\
\hline Preterm labour & 48 & 20.1 \\
\hline CPD & 37 & 15.4 \\
\hline Fetal distress & 29 & 12.1 \\
\hline Obstructed labour & 8 & 3.3 \\
\hline
\end{tabular}

Table 4 describes the intrapartum complications in teenage pregnancy preterm labour $48(20.1 \%)$, Cephalon Pelvic Disproportion 37(15.4 \%), fetal distress 29(12.1\%), obstructed labour 8(3.3\%).

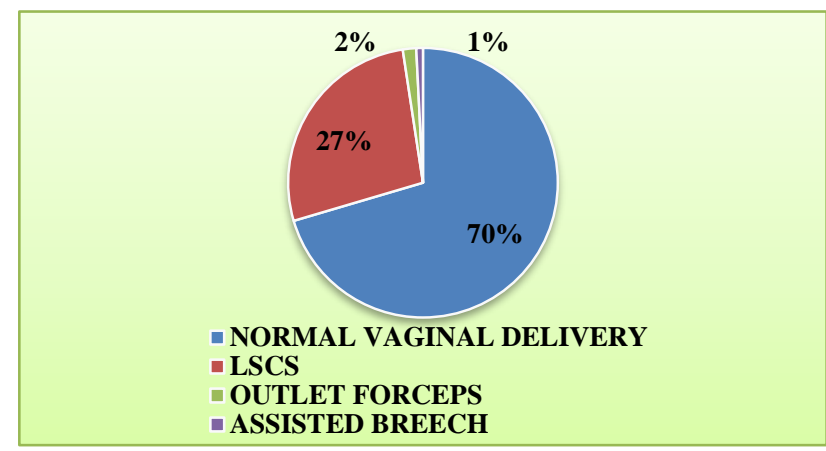

Figure 2: Outcome of teenage pregnancy at MGMGH.

Figure 2 describes outcome of teenage pregnancy at MGMGH-239(5.3\%) deliveries out of 4508 total deliveries during the study period.

Table 5: Postpartum complications of teenage pregnancy.

\begin{tabular}{|l|l|l|}
\hline Type of complication & No. of cases & Percentage \\
\hline PPH & 36 & 15.1 \\
\hline Puerperal sepsis & 5 & 2 \\
\hline Retained placenta & 1 & 0.4 \\
\hline
\end{tabular}

Out of 239 deliveries -Normal vaginal delivery $168(70.29 \%)$ and lower segment caesarean section $65(27.1) \%$, Assisted breech 2(0.8\%) and outlet forceps delivery $4(1.6 \%)$.

Table 5 shows postpartum complications that occurred in teenage pregnancy Primary PPH 36(15.1\%), Puerperal sepsis $5(2 \%)$, Retained placenta $1(0.4 \%)$.

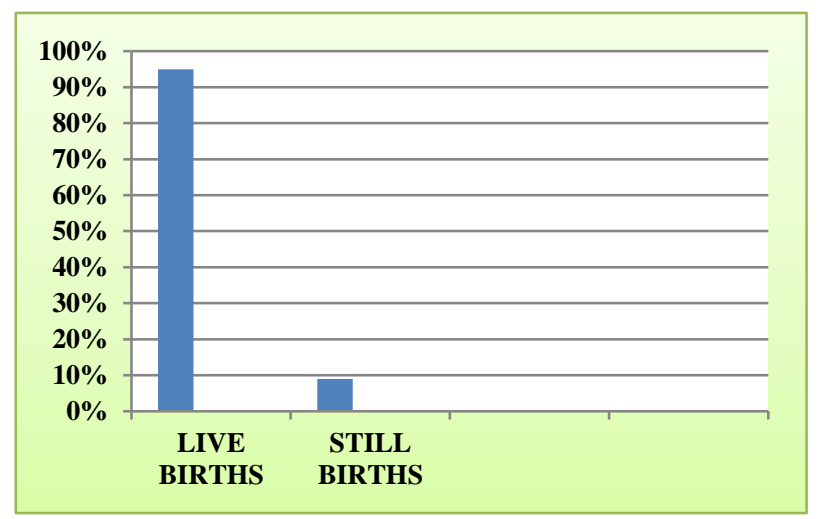

Figure 3: Neonatal outcome at MGMGH.

There were 2 twins; hence total babies born were 241 , $219(91.5 \%)$ were live births,22(9.1\%) were still births. $187(77.5 \%)$ were full term and $54(22.3 \%)$ were preterm babies (Figure 3).

Table 6: Neonatal complications in teenage pregnancy.

\begin{tabular}{|l|l|l|}
\hline Type of complications & No. of babies & Percentage \\
\hline Preterm & 54 & 22.3 \\
\hline Low birth weight & 76 & 31.5 \\
\hline IUGR & 41 & 17.1 \\
\hline NICU admission & 68 & 28.2 \\
\hline Perinatal death & 7 & 2.9 \\
\hline
\end{tabular}

Table 6 shows the Neonatal complications in teenage pregnancy preterm babies $546(22.3 \%)$, low birth weight babies<2.5kg $76(31.5 \%), 165(68.4 \%)$ babies birth required new-born intensive care admissions, perinatal death $7(2.9 \%)$.

\section{DISCUSSION}

Teenage pregnancy is a serious challenge for the health care system and a burden for the social infrastructure. In present study the incidence of Teenage pregnancy at our MGMGH was $5.56 \%$ which was low when compared with national incidence $7.9 \%$. In our state it was achieved due to declining trend of child marriage, improvement in education, socioeconomic status, improvement in health care services, good antenatal care, institutional deliveries and postnatal care.

At MGMGH 211 (84\%) of pregnant adolescents were primigravida, 34(13.54\%), 34(13.5\%) were second 
gravid,6(2.3\%) were third gravida. Higher incidence was found in primigravida.

According to NFHS-4, Women educational status is also found to be negatively associated with the prevalence of child marriage and adolescent pregnancy amongst 15-19 years. In present study $165(65.8 \%)$ had primary education and $86(34.2 \%)$ had secondary education. The single most important socio demographic determinant was literacy especially female literacy. The role of literacy in reducing the magnitude of the problems shown by the low incidence of teenage pregnancy in Kerala $(0.3 \%)$. Early marriage in our society was associated with low levels of schooling and education as well as early pregnancies. Attainment of higher education is associated with better awareness and wisdom, and consequently an urge for professional pursuit and desire for economic independence. This in turn leads to late marriage and conception. preventing unintended adolescent pregnancies and investing in girl's education, health and rights have powerful effects in other areas of life. Educated young women know their rights and offer a powerful boost to their families.

According to NFHS-4 Data the prevalence of child marriage amongst 15-19 years was $11.9 \%$ and in rural it was $14.1 \%$ and urban areas $6.9 \%$. most child marriages result in teenage pregnancy due to societal pressure and lack of sexual and reproductive health knowledge. $27.3 \%$ married teenage girls have given birth to one child and $4.2 \%$ have 2 or more children.

In present study anaemia $(47.1 \%)$ was found to be two times higher in the teenage pregnancy than in the adult group this may be due to inadequate nutritionist occurs due to poor eating habits which is common in adolescents. Severe anaemia leads to preterm labour, low birthweight, and related complications, postpartum hemorrhage and sepsis.in addition to impaired physical and cognitive development, and increased risk of morbidity in children and reduced work productivity in adults. Anaemia contributes to $20 \%$ of all maternal deaths. Iron deficiency anaemia is one of the most common causes of anaemia during pregnancy that can be corrected by proper diet and oral iron supplementation. ${ }^{7}$

Gestational hypertension (23.1\%) and eclampsia (4.8\%) occurred in present study group. There is high incidence of PIH and eclampsia in adolescent pregnancy. It is the most common complication of pregnancy amongst women having their first child and is therefore a common complication for many adolescent mothers. ${ }^{8}$

Teenage mothers should be counselled to have regular antenatal checkups for early detection of complications related to both mother and fetus. Adequate antenatal, intrapartum and postpartum as well as neonatal care can minimize the risk associated with childbirth and its effect on maternal and child health. Preterm labour occurred $(22.3 \%)$ in present study group which shows higher incidence. Bhalerao A et al, and Chahande MS have reported association between higher incidence of preterm labour in teenage pregnancy., ${ }^{9,10}$

In present study the adolescent pregnant women delivered by normal vaginal delivery $(70.29 \%)$ and lower segment caesarean section $65(27.1) \%$. There is no much difference between caesarean delivery rates in present study. Opinions on mode of delivery by operative interventions in teenage pregnancy differed widely AIRamahi et al reported that because of CPD there is higher rate of operative interventions and instrumental deliveries. ${ }^{11,12}$ But in present study there is no such higher incidence of LSCS and instrumental deliveries and compared with Eure CR e al, who reported lower rates of operative interventions. ${ }^{13}$

Low birth weight $(31.5 \%)$ and preterm babies $(22.3 \%)$ and neonatal complications are more common in adolescent pregnancy. ${ }^{14,15}$ Prianka $\mathrm{M}$ et al have the similar incidence of $38.9 \%$ of low birth weight babies in adolescent pregnancy. Low birthweight is a key indicator of malnutrition and important determinant of child mortality. No maternal mortality was reported in present study.

\section{CONCLUSION}

The present study aimed to evaluate the outcomes and complications of teenage pregnancy. It was concluded from the present study that preterm labour, hypertensive disorders of pregnancy, premature rupture of membranes, anaemia were major maternal complications. IUGR, low birth weight, stillbirth was major adverse fetal outcomes. The health care provider should consider teenage pregnancy as a high risk pregnancy and should educate the pregnant teenagers to have more number of antenatal visits so that the signs and symptoms of various complications of teenage pregnancy could be recognised at the earliest.

Proper antenatal care, institutional delivery and postnatal care help in reducing maternal and perinatal morbidity and mortality in adolescent pregnancy. Prevention of adolescent pregnancy can only be achieved by education of girl child, marriage at legal age, prevention of unwanted pregnancy along with proper health and life skill education to both boys and girls irrespective of whether they live in rural or urban areas. School based sexuality programs are needed that will provide student with knowledge of pregnancy, contraception and sexually transmitted diseases.

\section{ACKNOWLEDGMENTS}

Authors gratefully acknowledge and express sincere thanks to Dean, Government K. A. P. V. Medical College and, Mahatma Gandhi Memorial Government Hospital, Trichy, Tamil Nadu, South India, for allowing to do this study and utilizing the institutional facilities. 
Funding: No funding sources

Conflict of interest: None declared

Ethical approval: The study was approved by the Institutional Ethics Committee

\section{REFERENCES}

1. Chen XK, Wen SW, Fleming N, Demissie K, Rhoads GG, Walker M. Teenage pregnancy and adverse birth outcomes: a large population based retrospective cohort study. Int $J$ Epidemiol. 2007;36(2):368-73.

2. Government of India, National family health survey NFHS-4 2015-2016:3-24. Available at: http://dhsprogram.com/pubs/pdf.

3. Mayor S. Pregnancy and childbirth are leading causes of death in teenage girls in developing countries. BMJ: Brit Med J. 2004;328(7449):1152.

4. Agarwal N, Reddaiah VP. Factors affecting birth weight in a sub-urban community: A study in a secondary level hospital in Delhi. Health and Population-Perspectives and Issues. 2005;28(4):18996.

5. Bott S, Jejeebhoy SJ, Shah IH, Puri CP, World Health Organization. Towards adulthood: Exploring Sexual Reprod Health Adoles South Asia.

6. WHO. Preventing early pregnancy and poor reproductive outcomes among adolescents in developing countries. Geneva; WHO; 2011.

7. Cunningham FG, Kenneth JL, Bloom SL, John C, Hauth JC, Rouse DJ, et al. Obstetric complications. In: Williams Obstetrics. 23 ${ }^{\text {rd }}$ ed. Mc Graw Hill: New York; 2010:1079-1081.

8. WHO. 2004. Adolescent pregnancy, Issues in Adolescent Health and Development: 21-22.
9. Turner RJ, Grindstaff CF, Phillips N. Social support and outcome in teenage pregnancy. J Health Social Behavior.1990:43-57.

10. Chahande MS, Jadhao AR, Wadhva SK, Ughade S. Study of some epidemiological factors in teenage pregnancy hospital-based case comparison study. Indian J Communit Med. 2002;27(3):106-9.

11. Mukhopadhyay P, Chaudhuri RN, Paul B. Hospitalbased perinatal outcomes and complications in teenage pregnancy in India. J Health Populat Nutrit 2010;28(5):494.

12. Al-Ramahi M, Saleh S. Outcome of adolescent pregnancy at a university hospital in Jordan. Archives Gynecol Obstet. 2006;273(4):207-10.

13. Eure CR, Lindsay MK, Graves WL. Risk of adverse pregnancy outcomes in young adolescent parturients in an inner-city hospital. Am J Obstet Gynecol. 2002;186(5):918-20.

14. Conde-Agudelo A, Belizán JM, Lammers C. Maternal-perinatal morbidity and mortality associated with adolescent pregnancy in Latin America: Cross-sectional study. Am J Obstet Gynecol. 2005;192(2):342-9.

15. Olausson PM, Cnattingius S, Goldenberg RL. Determinants of poor pregnancy outcomes among teenagers in Sweden. Obstet Gynecol. 1997;89(3):451-7.

Cite this article as: Devi G, Kayalvizhi, Poovathi M. Study of fetomaternal outcome of teenage pregnancy in a tertiary care hospital-MGMGH. Int J Reprod Contracept Obstet Gynecol 2019;8:303-7. 